\title{
Linear probe 19-gauge endobronchial ultrasound diagnosis of a benign chondroid hamartoma
}

\author{
Janet Fallon1, Martin Plummeridge1, Richard Daly², Andrew Medford1 \\ 1 North Bristol Lung Centre, Southmead Hospital, Westbury-on-Trym, Bristol \\ 2 Department of Cellular Pathology, Southmead Hospital, Westbury-on-Trym, Bristol, UK
}

\begin{abstract}
We report a case of a 68 -year-old gentleman, found to have a right hilar soft tissue mass whilst undergoing CT staging for prostate cancer. MRI imaging showed a heterogeneous, enhancing solid mass without evidence of fat content. A linear probe endobronchial ultrasoundguided transbronchial needle aspiration was performed using a 19G needle. This confirmed the diagnosis of a benign chondroid hamartoma, avoiding the need for more invasive surgical biopsy.
\end{abstract}

\section{Case Report}

A 68-year-old gentleman with a recent diagnosis of prostate cancer was referred to the lung cancer multi-disciplinary team meeting by the uro-oncology team following a CT staging scan. The patient had no respiratory symptoms or prior respiratory history. The CT scan showed a well-defined soft tissue mass $(2.9 \times 2.9 \times 3.3 \mathrm{~cm})$ in the right lower lobe, adjacent to the posterior wall of the bronchus intermedius (Figure 1). There was no evidence of axillary, supraclavicular or mediastinal lymphadenopathy and no evidence of abdominopelvic disease elsewhere.

Corresponding author: Dr Andrew R.L. Medford, Consultant \& Honorary Senior Lecturer in Respiratory Medicine, North Bristol Lung Centre, Level 6 Gate 10, Brunel Building, Southmead Hospital, Westbury-on-Trym, Bristol BS10 5NB, UK. Tel. +44.1174.146340 - Fax +44.1174.149457.

E-mail: andrewmedford@hotmail.com

Key words: Chondroid hamartoma; EBUS-TBNA; 19 gauge; pulmonary nodule.

Contributions: JF, AM, conceived the idea and wrote the manuscript; all authors acquired the data and reviewed the manuscript.

Conflict of interest: The authors have no conflict of interest to declare.

Received for publication: 16 October 2017

Accepted for publication: 28 January 2018

(C) Copyright J. Fallon et al., 2018

Tipografia PI-ME Editrice, Italy

Monaldi Archives for Chest Disease 2018; $88: 890$

doi: 10.4081/monaldi.2018.890

This article is distributed under the terms of the Creative Commons Attribution Noncommercial License (by-nc 4.0) which permits any noncommercial use, distribution, and reproduction in any medium, provided the original author(s) and source are credited.
The diagnosis of prostate cancer had been made on the basis of a raised prostate specific antigen (PSA) of $136 \mathrm{ug} / \mathrm{l}$ and a positive prostate biopsy showing grade 2 moderately differentiated adenocarcinoma. Skeletal scintigraphy showed no evidence of skeletal metastases.

CT imaging raised the possibility that the lesion could be cystic in nature, and so a magnetic resonance imaging (MRI) scan of the thorax was arranged to further elucidate the structure of the lesion (Figure 2). This showed a heterogenous enhancing solid mass without evidence of fat content. It was felt that this could represent a carcinoid tumour or a metastatic lesion from prostatic carcinoma.

The patient started neo-adjuvant hormonal therapy and a linear probe endobronchial ultrasound-guided trans-bronchial needle aspiration (EBUS TBNA) was performed as previously described [1]. The linear probe EBUS showed a $24 \mathrm{~mm}$ heterogenous lesion arising from the posterior aspect of the right main bronchus, with areas of high density within a low echoic mass (Figure 3 ).

Six biopsies were taken using an Olympus 19G needle (Olympus ViziShot, NA-U402SX-4019, Olympus KeyMed, UK), ranging from 4-10 $\mathrm{mm}$ in size. These samples comprised several cores of hyaline cartilage (Figure 4), together with strips of respiratory epithelium and mucus-containing macrophages. Additional adipose tissue, fibrotic stroma and oedematous stroma covered by cuboidal epithelium with bland morphology were present in the sample (Figure 5). This combination of features was consistent with sampling of a benign chondroid hamartoma.

The patient went on to have high dose rate brachytherapy and external beam radiotherapy for the prostate cancer, and continues on hormonal therapy. This PSA is now normal at $0.8 \mathrm{ug} / \mathrm{l}$. A follow-up CT scan performed at an interval of 6 months showed no change in the size of the nodule. He remains under expectant review in the respiratory clinic and is asymptomatic from the chondroid hamartoma. Further surveillance imaging and clinical assessment is planned at a further interval of 12 months.

\section{Discussion}

Pulmonary hamartomas account for around 10\% of solitary pulmonary nodules and are often found incidentally on CT scanning. The majority are located peripherally. The presence of fat within the lesion can help to clarify the diagnosis, with the majority of fat-containing pulmonary lesions representing hamartomas [2]. MRI imaging can be used to further elucidate the structure of these lesions [2].

EBUS-TBNA is now widely used as the first line investigation for sampling mediastinal and hilar adenopathy, both for the diagnosis and staging of malignant disease and in non-malignant disease [1,3]. Although our centre has used linear probe EBUS-TBNA since 2009 [4] for benign and malignant mediastinal conditions, this is the first case of chondroid hamartoma we have diagnosed using linear probe $19 \mathrm{G}$ 


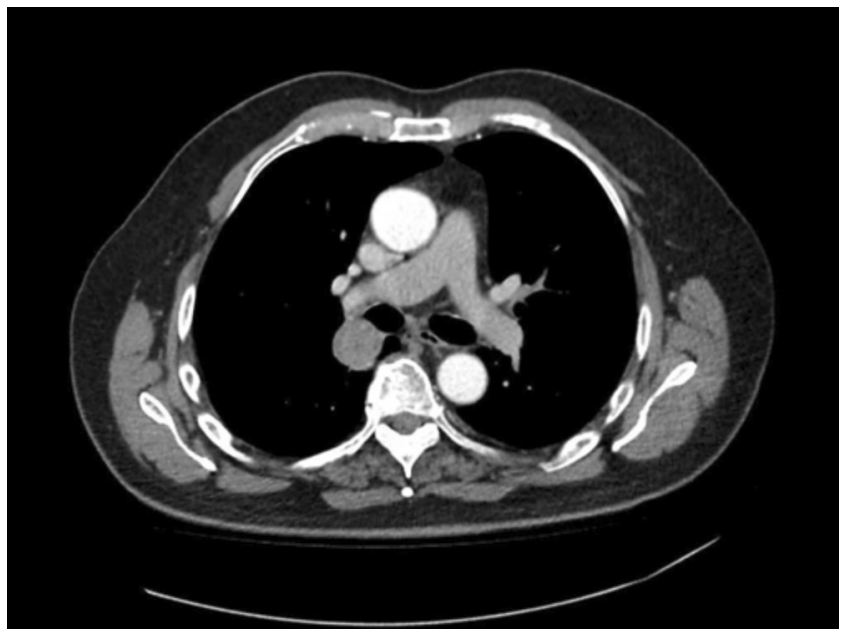

Figure 1. CT thorax showing soft tissue mass adjacent to the posterior wall of the bronchus intermedius.

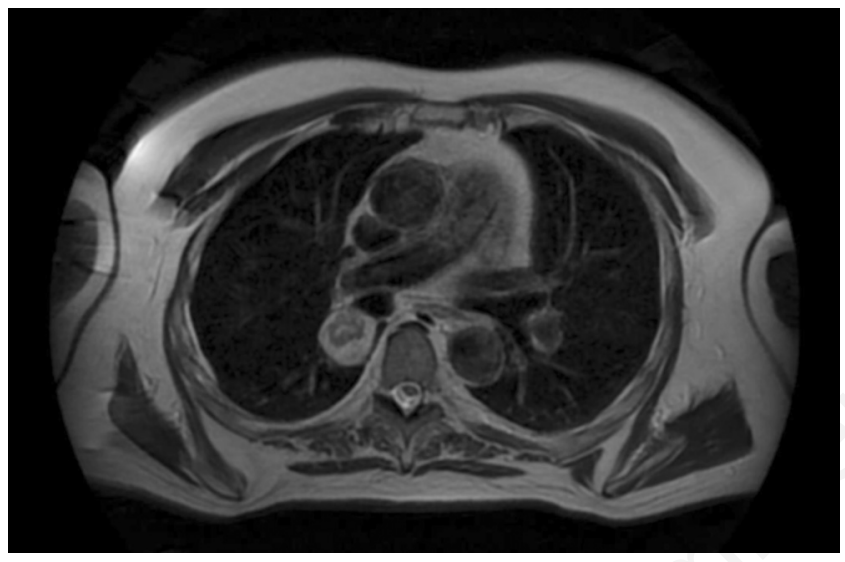

Figure 2. T2-weighted MRI of the thorax showing heterogeneous mass with enhancement.

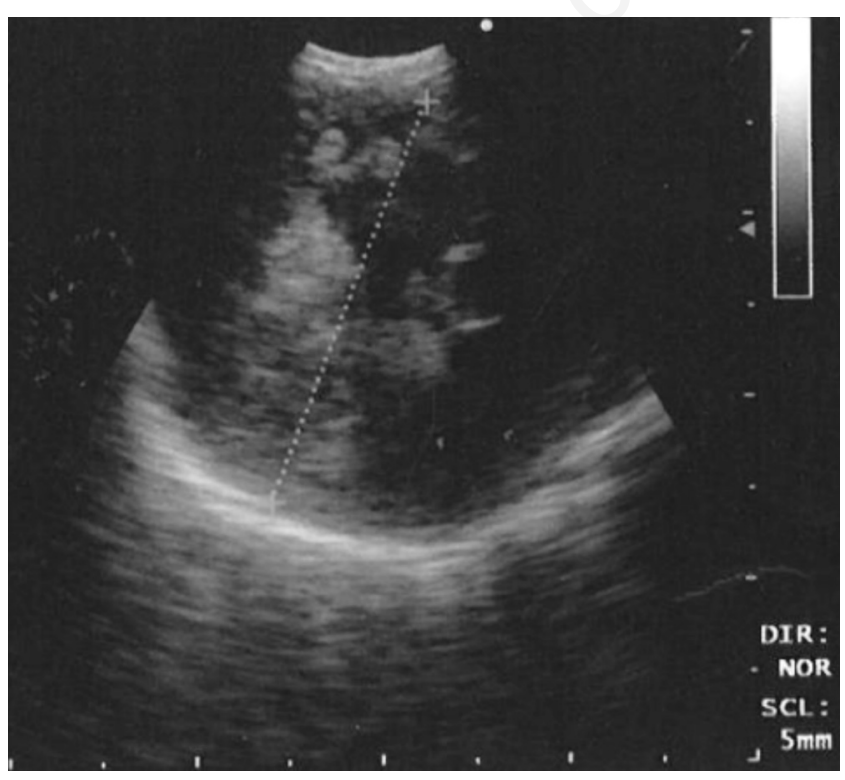

Figure 3. Endobronchial ultrasound images from the posterior aspect of the right main bronchus showing $24 \mathrm{~mm}$ heterogeneous mass.
EBUS-TBNA. This diagnostic modality allowed us to exclude metastatic prostate cancer and diagnose a benign condition requiring no further invasive treatment. We speculate the use of the $19 \mathrm{G}$ needle may have been pivotal here, as the 19G EBUS-TBNA needle has only recently become available, and offers more flexibility yet larger tissue samples. This is potentially advantageous compared with the existing $21 \mathrm{G}$ and $22 \mathrm{G}$ needles for the diagnosis of lymphoma and benign disease phenotyping where theoretically more tissue may be needed.

Two previous cases of pulmonary hamartoma diagnosed with EBUSTBNA have been reported in the literature using a smaller $22 \mathrm{G}$ needle where the findings were suggestive [5,6], however this is the first reported case of linear probe EBUS-TBNA using a $19 \mathrm{G}$ needle to diagnose a chondroid hamartoma and with greater confidence from the histological findings. Some published studies have already suggested that using a larger gauge needle at EBUS-TBNA can improve diagnostic rates, particularly in benign disease [7]. Otherwise, cases of chondroid hamartoma usually require either more invasive transbronchial biopsy or surgical biopsy. First experience of the use of $19 \mathrm{G}$ needles from other centres and our centre has demonstrated a promising diagnostic yield $[8,9]$.

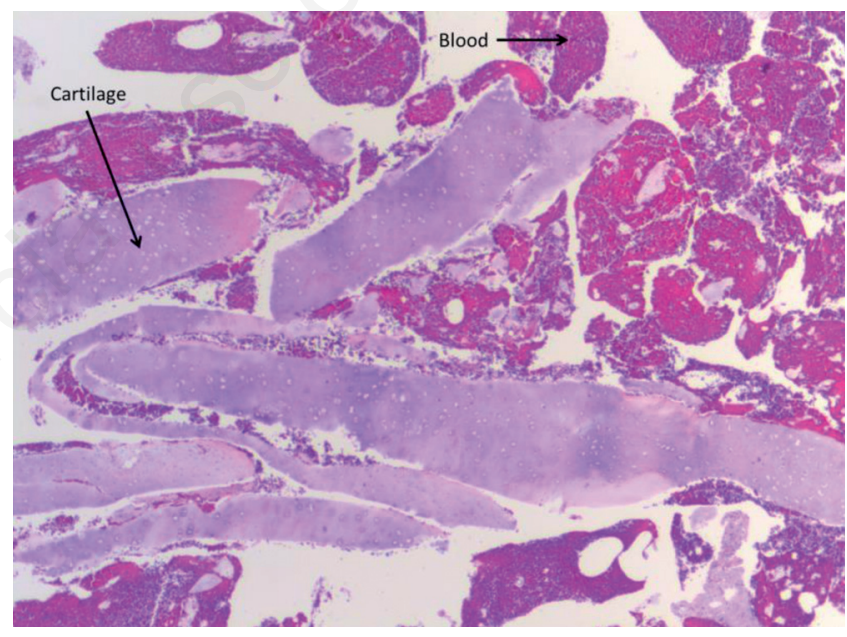

Figure 4. EBUS TBNA biopsy showing cartilage and blood.

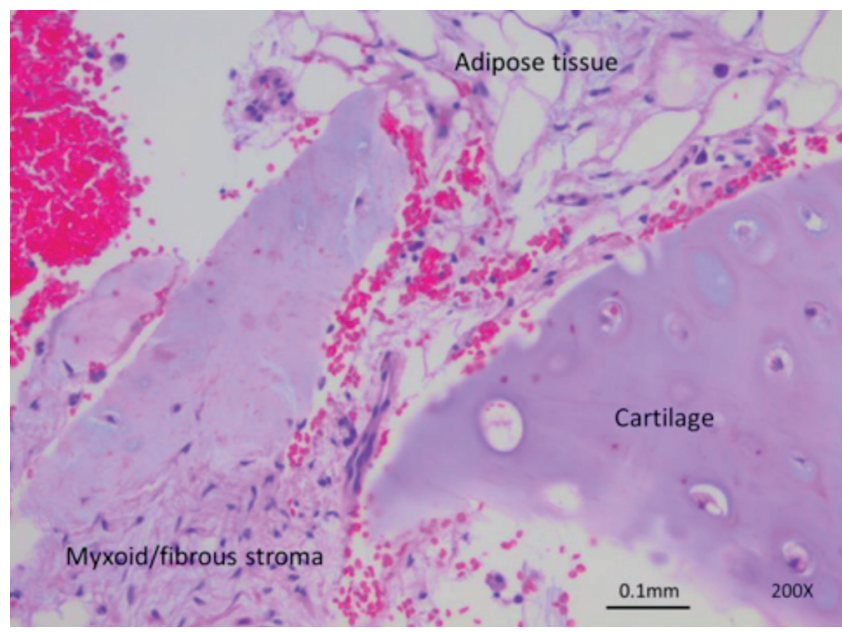

Figure 5. EBUS TBNA biopsy showing cartilage and surrounding tissues. 


\section{Conclusions}

Future comparative studies are required between $19 \mathrm{G}$ and $21 \mathrm{G}$ and $22 \mathrm{G}$ needles to clarify any diagnostic superiority. In the interim, we advocate the use of 19G EBUS-TBNA needle for lesions where an unusual diagnosis is anticipated, unclear benign entities or suspected lymphoproliferative disease. This may avoid the need for more invasive biopsies while allowing a confident benign diagnosis.

\section{References}

1. Medford AR, Bennett JA, Free CM, et al. Mediastinal staging procedures in lung cancer: EBUS, TBNA and mediastinoscopy. Curr Opin Pulm Med 2009;15:334-42.

2. Ost D, Fein AM, Feinsilver SH. Clinical practice. The solitary pulmonary nodule. N Engl J Med 2003;348:2535-42.

3. Homewood R, Darby M, Medford AR. Bronchogenic cyst mimicking an isolated paratracheal lymph node. Br J Hosp Med 2017;78:52-3.
4. Medford AR, Agrawal S, Free CM, et al. A performance and theoretical cost analysis of endobronchial ultrasound-guided transbronchial needle aspiration in a UK tertiary respiratory centre. QJM 2009;102:859-64.

5. Hata Y, Isobe K, Sasamoto S, et al. Pulmonary hamartoma diagnosed by convex probe endobronchial ultrasound-guided transbronchial needle aspiration (EBUS-TBNA). Intern Med 2010;49:1171-3.

6. Kajikawa S, Imai N, Takashima K, et al. Endobronchial ultrasound echoic image of pulmonary hamartoma. Respirol Case Rep 2014;2:85-6.

7. Jeyabalan A, Shelley-Fraser G, Medford AR. Impact of needle gauge on characterization of endobronchial ultrasound-guided transbronchial needle aspiration (EBUS-TBNA) histology samples. Respirology 2014;19:735-9.

8. Tyan C, Patel P, Czarnecka K, et al. Flexible 19-gauge endobronchial ultrasound-guided transbronchial needle aspiration needle: First experience. Respiration 2017;94:52-7.

9. Jones R, Medford AR. The effect of 19G EBUS-TBNA biopsies on characterisation of malignant and benign disease. Eur Respir $\mathrm{J}$ 2017;50(Suppl 61):PA832. 